\title{
Rare Association of Autoimmune Haemolytic Anaemia with Graves' Disease- Case Report
}

\author{
KM Suryanarayana ${ }^{1}, K_{\text {Sumana }}{ }^{2}$ \\ ${ }^{1}$ Professor, Department of Endocrinology, ${ }^{2}$ Senior Resident, Department of Endocrinology, M S Ramaiah Medical College, \\ MSRIT Post, Bengaluru-560054, Karnataka, India
}

Corresponding author: KM Suryanarayana, Professor, Department of Endocrinology, M S Ramaiah Medical College, MSRIT Post, Bengaluru-560054, Karnataka, India

DOI: http://dx.doi.org/10.21276/ijcmsr.2020.5.2.28

How to cite this article: KM Suryanarayana, K Sumana. Rare association of autoimmune haemolytic anaemia with graves' disease- case report. International Journal of Contemporary Medicine Surgery and Radiology. 2020;5(2):B113-B115.

\section{A B S T R A C T}

Introduction: Graves' disease is a common thyroid disorder with features of thyrotoxicosis and often associated with various types of anaemia, such as iron deficiency anaemia, pernicious anaemia, Graves' disease anaemia and autoimmune haemolytic anaemia. Autoimmune haemolytic anaemia is a rare association with Graves' disease.

Case Report: A 30 year old lady presented with complaints of thyrotoxicosis of one year duration and having been treated with multiple blood transfusions and vitamin B12 injections. Investigations confirmed thyrotoxicosis and also revealed severe coombs positive autoimmune haemolytic anaemia. She was treated initially with carbimazole and beta blockers. As there was no remission of Graves' disease and with associated refractory anaemia, she was ablated with radioactive iodine, after one year of carbimazole therapy. As autoimmune haemolytic anaemia persisted even after ablation, further treatment with glucocorticoids resulted in good response and gradual improvement of haemoglobin. Post ablation hypothyroidism was managed with long term levothyroxine replacement.

Conclusion: Autoimmune haemolytic anaemia and Graves' disease, both being autoimmune disorders, are very rarely associated. Features of haemolysis in a patient of Graves' Disease with anaemia may be a pointer for further evaluation and to reach at a correct diagnosis. Anti thyroid drug therapy may result in resolution of anaemia but corticosteroids are often required to treat refractory anaemia.

Keywords: Autoimmune Haemolytic Anaemia, Graves' Disease, Anaemia, Carbimazole

\section{INTRODUCTION}

Graves' disease (GD) is estimated to affect $0.5 \%$ of the population and accounts for up to $80 \%$ of hyperthyroidism cases and is more common in women than men. In addition to the usual clinical manifestations, GD patients may present with anaemia. Various types of anaemia are seen in or in association with GD, like iron deficiency anaemia, pernicious anaemia, GD anaemia and autoimmune haemolytic anaemia (AIHA). Autoimmune haemolytic anaemia is a rare association with GD and we report one such case.

\section{CASE REPORT}

A thirty year old lady presented with complaints of severe generalized weakness, palpitations, weight loss and irregular menstrual cycles of nearly one year duration and had received two units of blood transfusion and multiple vitamin B12 injections during this period. On examination she had marked pallor, mild icterus, tachycardia, grade 2 diffuse goitre and no orbitopathy. She had no lymphadenopathy, hepatomegaly or splenomegaly. Rest of the clinical examination was unremarkable. Investigations revealed evidence of severe anaemia, haemolysis and thyrotoxicosis: $\mathrm{Hb}-5.4 \mathrm{~g} / \mathrm{dL}(11.5-16.5)$, TLC-6200 cells/cu mm(400011000), Platelet count-3,60,000 cells/cu mm(1,50,000$4,50,000)$, BUN-12 mg/dL(7-20), Serum creatinine- $0.7 \mathrm{mg} /$ $\mathrm{dL}(0.6-1.1), \mathrm{MCV}-142 \mathrm{fL}(80-100)$, Reticulocyte count 6.5\%(0.2-2.0), Total bilirubin-2.8mg/dL(0.3-1.0), Indirect bilirubin-2.5mg/dL, Direct bilirubin-0.3mg/dL(0-0.3),

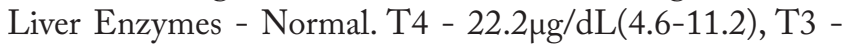
$3.97 \mathrm{ng} / \mathrm{mL}(0.8-1.8), \mathrm{TSH}<0.05 \mu \mathrm{U} / \mathrm{mL}(0.4-4)$. Technetium 99 scan of thyroid revealed diffuse, uniform and increased uptake in both lobes, consistent with the diagnosis of Graves' disease. Further haematological evaluation revealed coombs positive autoimmune haemolytic anaemia. Patient was treated with carbimazole and beta blockers and as there was no remission of GD or refractory anaemia, even after one year of treatment, she was ablated with $10 \mathrm{mc}$ of radioactive iodine. Post ablation hypothyroidism was managed with long term levothyroxine replacement. As AIHA persisted, she was treated with glucocorticoids with good response and gradual improvement of haemoglobin.

\section{DISCUSSION}

Graves' disease (GD) is the most common cause of 
hyperthyroidism affecting $0.5 \%$ of the population. ${ }^{1}$ Compared to men, women are 4 to 5 times more commonly affected. GD affects almost all organs and systems of the body including haematopoietic system and all the three cell lineages are affected with abnormalities noted in erythrocytes, leukocytes and platelets.

Anaemia is found in 33\% of GD patients. ${ }^{2}$ The erythrocytes can be normocytic, microcytic or macrocytic. Very rarely it can cause increase in haemoglobin A2 levels and can mimic $\beta$ thalassemia. ${ }^{3}$ Four types of anaemia are described either with or in association with GD. These include Graves' disease anaemia, pernicious anaemia, iron deficiency anaemia and AIHA. GD anaemia resembles anaemia of chronic disease in many aspects, such as red cell morphology (MCV is low or normal), iron status, erythropoietin levels and markers of inflammation. This type of anaemia usually resolves once euthyroid state is achieved regardless of the type of therapy used. Pernicious anaemia (PA), being an autoimmune disorder occurs in association with GD, with a prevalence of $1.4 \% .^{4}$ The presence of macrocytes with hyper segmented polymorphonuclear leukocytes on the peripheral smear provides clue to the presence of PA in GD patients. Iron deficiency anaemia can result from either due to blood loss (occult or obvious) or due to coeliac disease, which has a prevalence of about $0.9 \%$ among GD patients. ${ }^{4}$ The association of AIHA with GD was first noted in 1978 and this association is very rare and is limited to only few case reports where it occurred alone or in combination with immune thrombocytopenic purpura, as a part of Evans' syndrome. ${ }^{5,6}$ We report one such case of AIHA in a lady with GD.

There are two explanations offered for the haemolysis of the red blood cells in GD, namely immune mechanism and dynamic hyperthyroid state of the GD. To support the immune mechanism as a cause, there are some case reports where AIHA occurred even after the patient became euthyroid after treatment with either anti thyroid drugs or Radioactive iodine ablation (RAI). ${ }^{6}$ It is well known that presence of one autoimmune disease predisposes to another. This could be either due to genetic susceptibility that predisposes to two diseases or the presence of one disease that alters homeostasis in the body and predisposes to another disease. ${ }^{7}$ Moreover both TSH receptor antibody and warm autoantibody in AIHA are of igG type. TSH receptor antibody could attach to erythrocytes non-specifically and cause haemolysis. Reducing the level of TSH receptor antibodies by means of anti thyroid drug therapy could have immunosuppressive effects and lead to resolution of AIHA. ${ }^{8}$ Girelli.G et al evaluated 45 patients of AIHA for thyroid function and observed that 6 patients had thyroid autoantibodies and 4 had abnormal thyroid function tests. ${ }^{8}$

There are case reports to support hyperthyroidism per se as a cause of haemolysis rather than autoimmunity, where in haemolysis occurred in a case of TSH secreting pituitary adenomas. ${ }^{10}$ Hyperthyroidism leads to activation of reticuloendothelial system, which could lead to increased phagocytosis of antibody coated erythrocytes. Moreover there are interesting cases where AIHA resolved after correction of hyperthyroidism with antithyroid drugs like propylthiouracil without the use of corticosteroids. ${ }^{8}$ Our patient did not achieve euthyroid state, even after one year of treatment with carbimazole and she opted for radioactive iodine ablation. Subsequently after 3 months, she became hypothyroid and was advised levothyroxine replacement. However, haemolysis could not be controlled and she required definitive therapy with corticosteroids, after which her haemoglobin improved dramatically from $5.4 \mathrm{~g} / \mathrm{dL}$ to $12.2 \mathrm{~g} / \mathrm{dL}$ and presently she is on maintenance dose of steroids.

Lack of awareness about the rare association of AIHA with GD led to unnecessary blood transfusions and vitamin B12 injections in our patient for a period of one year before presenting to us (patient had macrocytes with MCV of 142, which could have led to false assumption of B12 deficiency anaemia/pernicious anaemia).

\section{CONCLUSION}

Graves' disease is associated with various types of anaemia. AIHA and GD, being autoimmune disorders are very rarely associated. It is very important to look for subtle clues of haemolysis when a GD patient presents with anaemia, so that a correct and timely diagnosis is made. Conversely thyroid function should be assessed in a patient with AIHA, so that subclinical thyrotoxicosis is not missed. Anti thyroid drug therapy could have immunosuppressive effects and lead to resolution of AIHA. Definitive therapy with corticosteroids is often required to treat refractory anaemia

\section{REFERENCES}

1. Brent GA. Graves' disease. New England Journal of Medicine. 2008;358(24):2594-605.

2. Gianoukakis AG, Leigh MJ, Richards P, Christenson PD, Hakimian A, Fu P, et al. Characterization of the anaemia associated with Graves' disease. Clinical endocrinology. 2009;70(5):781-7.

3. Akasheh MS. Graves' disease mimicking betathalassemia trait. Postgraduate medical journal. 1994;70(822):300-1

4. Boelaert K, Newby PR, Simmonds MJ, Holder RL, Carr-Smith JD, Heward JM, et al. Prevalence and relative risk of other autoimmune diseases in subjects with autoimmune thyroid disease. The American journal of medicine. 2010;123(2):183-e1.

5. Chee YC. Hyperthyroidism and autoimmune hemolytic anemia-A case report. Med J Malasia. 1978;33(3):1545.

6. Ikeda K, Maruyama Y, Yokoyama M, Kato N, Yamanoto H, Kaguchi Y, et al. Association of Graves' disease with Evans' syndrome in a patient with $\operatorname{IgA}$ nephropathy. Internal medicine. 2001;40(10):1004-10.

7. Sloka S. Observations on recent studies showing increased co-occurrence of autoimmune diseases. Journal of autoimmunity. 2002;18(3):251-7.

8. Ushiki T, Masuko M, Nikkuni K, Terukina-Yoshida J, Momotsu-Nanba A, Morikawa H, et al. Successful remission of Evans syndrome associated with Graves' disease by using propylthiouracil monotherapy. Internal Medicine. 2011;50(6):621-5.

9. Girelli G,Lio S, Adorno G,Perrone MP,D'Armiento M. Thyroid functioning in autoimmune hemolytic anemias. 
Scandinavian journal of haematology. 1986;37(3):266.

10. Yasuda A, Seki T, Oki M, Takagi A, Inomoto C, NAKAMURA N, et al. A Case of a TSH-secreting Pituitary Adenoma Associated with Evans' Syndrome. Tokai J Exp Clin Med. 2015;40(2):44-50.

Source of Support: Nil; Conflict of Interest: None

Submitted: 15-04-2020; Accepted: 17-05-2020; Published online: 30-06-2020 